ORIGINAL ARTICLE

\title{
A video questionnaire identifies upper airway abnormalities in preschool children with reported wheeze
}

\author{
S Saglani, S A McKenzie, A Bush, D N R Payne
}

See end of article for authors' affiliations ......................

Correspondence to: Dr D Payne, Senior Lecturer in Paediatric Respiratory Medicine, Royal Brompton Hospital, Sydney Street, London SW3 6NP, UK; d.payne@ imperial.ac.uk

Accepted 21 March 2005 Published Online First 26 April 2005

Background: Accurate characterisation of subjects is essential to interpret data from studies investigating preschool wheezing.

Aim: To assess whether a video questionnaire (VQ) identifies upper airway abnormalities in preschool children with reported wheeze.

Methods: Forty three children (median age 17 months, range 3-58) undergoing fibreoptic bronchoscopy for clinical investigation of troublesome noisy breathing at a tertiary centre were studied. Parents were shown a VQ with four clips (wheeze, stridor, and two other upper respiratory noises) and chose the clip(s) resembling their child's main symptom. Doctor observed symptoms, parental reported symptoms, and symptoms identified on VQ were related to bronchoscopy.

Results: Thirty subjects had wheeze as the main symptom: 19 had doctor observed wheeze (DOW) and 11 had parental reported wheeze (RW). Parents of two of the subjects with RW identified wheeze alone on VQ and both had normal bronchoscopic findings. Five of the remaining nine subjects with RW had upper airway abnormalities at bronchoscopy. Parents of six subjects with RW identified a noise other than wheeze on VQ; four of these had upper airway abnormalities. Parents of two subjects with RW did not identify a noise on VQ; one had upper airway abnormalities. Of the 19 with DOW, nine parents identified wheeze alone on VQ, and all had a normal upper airway. Parents of nine subjects with DOW identified a noise other than wheeze as an equal or only symptom, (no noise identified in one), and five had upper airway abnormalities.

Conclusion: A VQ helps to identify upper airway abnormalities in preschool children with a history of wheezing.

l order to interpret the results of studies investigating infant and preschool wheeze, it is important that patients selected are correctly characterised. Recurrent, troublesome wheeze in this age group is common. However, wheeze is often not present when the child is assessed, and confirmation of the symptom depends on parental reports and detailed history taking. Terms used by physicians when taking a history may be quite different to parents' understanding of those terms. ${ }^{1-5}$ This can partly be explained by differences in patients' and physicians' ethnic backgrounds, ${ }^{2}$ but is also due to parents adopting the term wheeze to describe a variety of different forms of noisy breathing. ${ }^{3}$ A recent study of preschool children with parental reports of wheeze showed worse lung function in those subjects in whom parental reports were confirmed by a doctor compared with those in whom the reports could not be confirmed. ${ }^{6}$ This highlights the importance of accurate classification of subjects for research.

In order to improve diagnostic accuracy and provide an objective means of eliciting wheeze, the use of a video questionnaire (VQ) may be helpful. ${ }^{2}$ In this study we assessed the relation between previous doctor observed respiratory symptoms, parental reports of symptoms, symptoms identified on VQ, and findings at bronchoscopy at a tertiary paediatric respiratory centre. The study aimed to assess whether a VQ can be used to identify the presence of an upper airway abnormality in preschool children with a history of wheezing. Findings from the VQ were validated with fibreoptic bronchoscopy for stridor and upper respiratory noises. This may strengthen the methodology available

for use in future research studies to characterise wheezers and non-wheezing "controls".

\section{METHODS}

Subjects

Eligible subjects included infants and children, aged 3-60 months, undergoing clinically indicated fibreoptic bronchoscopy (FOB), between January 2003 and June 2004, at a tertiary centre, for the investigation of troublesome, respiratory symptoms associated with noisy breathing.

\section{Reported symptom and video questionnaire}

The clinician classified the main reported symptom on the history given by the parent(s). Parents used the word "wheeze" when reporting that as a symptom. The word "stridor" was not used by parents, the symptom usually being described or imitated. Stridor was used by the clinician following their interpretation of the noise described. Many patients with parental reported wheeze (RW) had previously been assessed when acutely unwell, and so a record of previous doctor observed wheeze (DOW) was available. Similarly, many patients with stridor had been seen by a doctor when symptomatic. The patients were therefore divided into four groups: DOW, RW, doctor observed stridor (DOS), and reported stridor (RS). Parents were shown a VQ

Abbreviations: DOS, doctor observed stridor; DOW, doctor observed wheeze; FOB, fibreoptic bronchoscopy; RS, reported stridor; RW, parental reported wheeze; URN, upper respiratory noise; VQ, video questionnaire 
Table 1 Age, sex, ethnicity of subjects, and indications for bronchoscopy

\begin{tabular}{lll}
\hline & Wheeze & Stridor \\
\hline Number & 30 & 13 \\
Age (months) [median (range)] & $25.5(6-58)$ & $14(3-42)$ \\
Males & $17(57 \%)$ & $9(69 \%)$ \\
Ethnicity & $25(84 \%)$ & $8(62 \%)$ \\
$\quad$ Caucasian & $1(3 \%)$ & $2(15 \%)$ \\
$\quad$ Afro-Caribbean & 0 & $1(8 \%)$ \\
Indian & $2(7 \%)$ & $2(15 \%)$ \\
$\quad$ Arabic & $1(3 \%)$ & 0 \\
$\quad$ Chinese & $1(3 \%)$ & 0 \\
$\quad$ Mixed Indian/Caucasian & $19(63 \%)$ & 0 \\
Previous hospital admission for acute & & \\
wheeze & & 0 \\
Indication for FOB & 30 & 13 \\
$\quad$ Exclude other diagnoses and/or & & \\
identify upper airway abnormality & 0 & \\
Identify cause of stridor & & \\
\hline
\end{tabular}

by an observer who had not classified the main reported symptom. The previously validated video contained four clips, each lasting one minute, of infants and children showing examples of wheeze (male, aged 6 years), stridor (male, 6 months), and two different upper respiratory noises (both females, 10 and 24 months). ${ }^{2}$ The first upper respiratory noise
(URN) sounded like a child snoring. The second URN resembled that of loud mouth breathing. Parents were asked: "Which, if any, of the noises in this video does your child make?". They could choose none, one, or more than one clip. Although there were only two parental reported noises, wheeze or stridor, use of the VQ resulted in the possible identification of a third noise, URN.

The decision to perform a FOB was made by the child's clinician (table 1). All wheezers had previously failed a trial of steroid and/or bronchodilator therapy for recurrent wheezing.

\section{Fibreoptic bronchoscopy}

FOB was carried out under general anaesthesia by one of three clinicians. A size $2.7 \mathrm{~mm}$ bronchoscope was used for patients under 2 years, and a $3.6 \mathrm{~mm}$ bronchoscope (Olympus Keymed, UK) was used for those between 2 and 5 years. The bronchoscopist was unaware of the classification of symptom(s) identified on VQ. Findings were recorded as normal anatomy, or a structural or functional (malacia or external compression from a vascular ring) upper airway or central airway abnormality. Upper airway was defined as tonsils, adenoids, pharynx, and larynx. The central airway was defined as subglottis, trachea, and right and left main bronchi.

The study was approved by the local ethics committee and full parental consent was obtained.
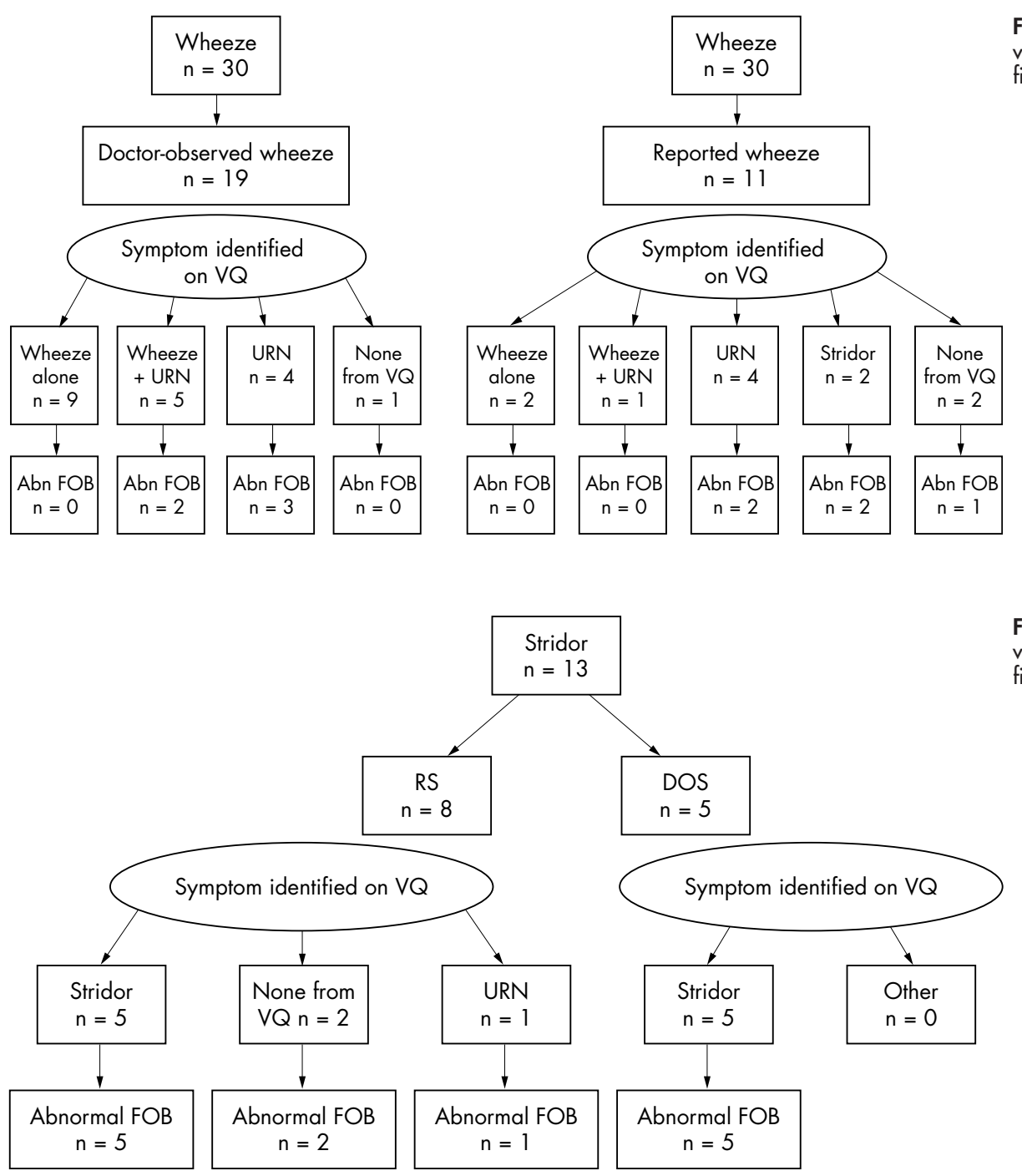

Figure 1 Relation between symptoms, video questionnaire, and bronchoscopy findings in subjects with wheeze.
Figure 2 Relation between symptoms, video questionnaire, and bronchoscopy findings in subjects with stridor. 
Table 2 Relation between bronchoscopic findings and identification of an upper respiratory noise (URN) or stridor on video questionnaire (VQ) in all patients with wheeze (both DOW and RW)

\begin{tabular}{lccl}
\hline & $\begin{array}{l}\text { Upper or central airway } \\
\text { abnormality on FOB }\end{array}$ & \multicolumn{2}{c}{ Normal upper and central } \\
airway on FOB & Total \\
\hline URN or stridor on VQ & 9 & 7 & 16 \\
No URN or stridor on VQ & 1 & 13 & 14 \\
Total & 10 & 20 & 30 \\
\hline
\end{tabular}

Table 3 Relation between symptom identified on video and findings at bronchoscopy

\begin{tabular}{|c|c|c|c|c|}
\hline \multirow[b]{4}{*}{ Symptom identified on video } & \multicolumn{4}{|c|}{ Reported symptom } \\
\hline & \multicolumn{2}{|c|}{ Wheeze $(n=30)$} & \multicolumn{2}{|l|}{ Stridor $(n=13)$} \\
\hline & \multicolumn{4}{|c|}{ Bronchoscopy finding } \\
\hline & $\begin{array}{l}\text { Normal } \\
\text { anatomy }\end{array}$ & $\begin{array}{l}\text { Upper or central } \\
\text { airway abnormality }\end{array}$ & Normal anatomy & $\begin{array}{l}\text { Upper or central } \\
\text { airway abnormality }\end{array}$ \\
\hline Wheeze alone & 11 & 0 & 0 & 0 \\
\hline Wheeze and URN & 4 & 2 & 0 & 0 \\
\hline Upper respiratory noise & 3 & 5 & 0 & 1 \\
\hline Stridor & 0 & 2 & 0 & 10 \\
\hline None & 2 & 1 & 0 & 2 \\
\hline
\end{tabular}

\section{RESULTS}

Forty three patients were included (table 1). Parents of 39/43 (91\%) patients spoke English fluently. A translator was used in the remaining four cases. The relation between doctor observed symptoms, parental reported symptoms, and findings from the VQ and FOB are summarised in figs 1 and 2 .

\section{Subjects with wheeze}

None of the patients with DOW or RW, whose parents identified wheeze alone on VQ, had any anatomical abnormality on bronchoscopy. Of the six subjects with RW whose parents identified an URN or stridor on VQ, four had abnormal upper or central airway findings at FOB (fig 1). Of the patients with wheeze, 10/30 parents identified an URN or stridor alone on the video. Seven of these 10 subjects (70\%) had abnormal upper or central airway findings at FOB.

Table 4 Abnormal findings at bronchoscopy related to symptom identified on video

\begin{tabular}{ll}
\hline $\begin{array}{l}\text { Symptom identified on } \\
\text { video }\end{array}$ & Bronchoscopy finding \\
\hline $\begin{array}{l}\text { Wheeze alone } \\
\text { Upper respiratory noise }\end{array}$ & $\begin{array}{l}\text { Normal anatomy (11) } \\
\text { Tracheal compression (1) } \\
\text { Laryngo-tracheomalacia (1) } \\
\text { Laryngomalacia (2) }\end{array}$ \\
& Normal (3) \\
Wheeze and URN & Large adenoids (1) \\
& Tracheomalacia (1) \\
& Normal (4) \\
Stridor & Laryngomalacia (5) \\
& Tracheomalacia (3) \\
& Enlarged tonsils and adenoids (1) \\
& Pulsatile tracheal compression (2) \\
& Compression of left main bronchus (1) \\
Enlarged tonsils and adenoids (2) & Compression of left and right main bronchi (1) \\
None & Normal (2) \\
\hline
\end{tabular}

Sensitivity and specificity of VQ in identifying upper airway abnormalities in patients with wheeze

Using FOB anatomical findings as the gold standard, the sensitivity of the VQ in correctly identifying patients with an upper or central airway abnormality was $90 \%$, and the specificity $65 \%$ (table 2 ).

\section{Subjects with stridor}

Parents of 10/13 (77\%) patients with stridor correctly identified stridor on video, and in all of these cases bronchoscopy revealed abnormal structural or functional airway anatomy. None of the parents whose child's main symptom was stridor recognised wheeze on the VQ (table 3 ).

\section{Relation between video questionnaire and bronchoscopy findings for all patients}

All patients whose parents identified wheeze alone on VQ had a normal upper airway at bronchoscopy. All patients whose parents identified stridor alone on VQ had an abnormal upper airway at bronchoscopy (table 3 ). The abnormal bronchoscopic findings are summarised in table 4 .

\section{DISCUSSION}

In this study of infants and preschool children, which included patients with both RW and DOW, the additional use of a VQ helped to identify the majority of those who had associated upper airway abnormalities.

When patients are recruited for research studies, the presence or absence of wheeze is usually defined on the basis of parental reports. In the current study, in cases of RW, application of the VQ as an adjunct to history taking confirmed the previously reported discrepancy between parental and physicians' understanding of the term wheeze. ${ }^{1-3}$ This was present even when most families were Caucasian and spoke English fluently. A limitation of the study was that one of the video clips used was of a boy aged 6 years. However, the symptoms and signs seen in the clip were typical of those seen in preschool children with wheeze. Also, both patients displaying an URN on the VQ were female, while the two patients with wheeze and stridor were male. It 


\section{What is already known on this topic}

- Accurate characterisation of subjects is essential to interpret data from studies investigating preschool wheeze; there is a discrepancy between parental and physicians' understanding of the term wheeze

- A study of preschool children with reported wheeze showed worse lung function in those subjects in whom reports were confirmed by a doctor compared with those in whom reports were not confirmed

is possible that parents may have chosen the clip that most closely resembled their own child, regardless of the respiratory noise. Although post-hoc analysis of the data does not support this suggestion (data not shown), it would be preferable to have a wider choice of clips available, in order to minimise the influence of the age, gender, and ethnicity of the patients in the video clips on parents' choice. Further limitations of this study include the relatively small number of patients, and use of the VQ at a tertiary centre only. The findings cannot therefore be generalised to patients in primary or secondary care. We also do not suggest that findings from the VQ should determine whether or not patients undergo FOB. However, the only way of validating the VQ findings was by performing FOB. Therefore the study could not have been performed in a less specialised setting. Although the small number makes calculations of sensitivity and specificity difficult to interpret, it is important to note that as a tool in this specialised setting, the VQ was sensitive at detecting upper airway abnormalities in patients with a history of wheeze.

This is the first report of the application of a VQ to parents of patients with stridor. We have shown that the identification of stridor on VQ was always associated with an upper or central airway abnormality on bronchoscopy. The VQ may therefore help to allow more secure identification of patients with isolated upper airway problems, who currently form the best control group for research studies involving bronchoscopy, as discussed in recent guidelines for bronchoscopic research. ${ }^{7}$

In summary, the application of a VQ in a tertiary setting is a useful additional tool that allows the identification of upper airway abnormalities in infants and preschool children with

\section{What this study adds}

- A video questionnaire helps to identify upper airway abnormalities in preschool children with reported wheeze

- A video questionnaire may play a role in the design of future studies investigating preschool wheeze

reported wheeze. We recommend that the use of a VQ should be considered in the design of future studies investigating wheeze in infants and preschool children, especially in a tertiary setting.

\section{ACKNOWLEDGEMENTS}

We are grateful to Dr Rachel Cane for making the video questionnaire. Also to Drs Mark Rosenthal and Ian Balfour-Lynn who performed some of the bronchoscopies.

\section{Authors' affiliations}

S Saglani, A Bush, D N R Payne, Paediatric Respiratory Medicine, Airways Diseases Section of the National Heart and Lung Institute, Imperial College, London, UK

S A McKenzie, Department of Paediatrics, The Royal London Hospital, London, UK

Funding: this study was supported by Asthma UK

Competing interests: none declared

\section{REFERENCES}

1 Cane RS, Ranganathan SC, McKenzie SA. What do parents of wheezy children understand by "wheeze"? Arch Dis Child 2000;82:327-32.

2 Cane RS, McKenzie SA. Parents' interpretations of children's respiratory symptoms on video. Arch Dis Child 2001;84:31-4.

3 Elphick HE, Sherlock P, Foxall G, et al. Survey of respiratory sounds in infants. Arch Dis Child 2001;84:35-9.

4 Shaw RA, Crane J, O'Donnell TV, et al. The use of a videotaped questionnaire for studying asthma prevalence. A pilot study among New Zealand adolescents. Med J Aust 1992;157:311-14.

5 Levy ML, Godfrey S, Irving CS, et al. Wheeze detection: recordings vs. assessment of physician and parent. J Asthma 2004;41:845-53.

6 Lowe L, Murray CS, Martin L, et al. Reported versus confirmed wheeze and lung function in early life. Arch Dis Child 2004;89:540-3.

7 Jeffery $\mathbf{P}$, Holgate S, Wenzel S. Methods for the assessment of endobronchial biopsies in clinical research: application to studies of pathogenesis and the effects of treatment. Am J Respir Crit Care Med 2003; 168:S1-17. 